\title{
Pengaruh Metode Latihan (Resiprokal dan Inklusi) Persepsi Kinestetik terhadap Teknik Overhead Lob Forehand Bulu Tangkis
}

\author{
Muhammad Husni Tamim \\ Program Studi Pendidikan Jasmani Kesehatan dan Rekreasi, Universitas Hamzanwadi. Jalan TGKM. \\ M. Zainuddin Abdul Madjid No. 132 Pancor, Selong, Lombok Timur, Indonesia \\ Email: husnitamim0@gmail.com
}

Received: 31 January 2017; Revised:26 April 2017; Accepted: 27 April 2017

\begin{abstract}
Abstrak
Tujuan penelitian ini adalah untuk mengetahui: (1) perbedaan pengaruh metode latihan resiprokal dan inklusi terhadap peningkatan teknik overhead lob forehand pada bulu tangkis. (2) Perbedaan keterampilan teknik overhead lob forehand bulu tangkis pada persepsi kinestetik tinggi dan persepsi kinestetik rendah. (3) Pengaruh interaksi antara metode latihan (resiprokal dan inklusi) dan persepsi kinestetik terhadap peningkatan teknik overhead lob forehand pada bulu tangkis. Penelitian ini menggunakan desain penelitian eksperimen faktorial. Teknik analisis data yang digunakan uji normalitas (Kolmogorov Smirnov) dan uji homogenitas (Levene) signifikansi a $=0.05$. Hasil penelitian menunjukkan bahwa: (1) ada perbedaan pengaruh antara metode latihan resiprokal dan inklusi terhadap keterampilan teknik overhead lob forehand pada bulu tangkis, (2) ada perbedaan antara keterampilan teknik overhead lob forehan bulu tangkis pada persepsi kinestetik tinggi dan persepsi kinestetik rendah, (3) tidak ada interaksi antara metode latihan (resiprokal dan inklusi) dan persepsi kinestetik terhadap keterampilan teknik overhead lob forehand pada bulu tangkis.
\end{abstract}

Kata Kunci: metode latihan resiprokal dan inklusi, persepsi kinestetik, dan peningkatan teknik overhead lob forehand pada bulu tangkis

\section{The Effect of Training Method (Reciprocal and Inclusion) and Kinesthetic Perception on the Improvement of Overhead Lob Forehand in Badminton}

\begin{abstract}
The objectives of this research are to know: (1) the effect difference of reciprocal and inclusion teaching methods on technique improvement of overhead lob forehand in badminton, (2) the difference of overhead lob forehand technique skill in badminton in high kinesthetic perception and low kinesthetic perception, and (3) the interaction effect of training method (reciprocal and inclusion) and kinesthetic perception on technique improvement of overhead lob forehand in Badminton. The research employed factorial experiment research design. The data analysis techniques used were normality test (Kolmogorov Smirnov) and homogeneitytest (Levene) with the significance of a $=0.05$ The result of this research shows that: (1) there are significant effect differences between reciprocal and inclusion training method on overhead lob forehand technique skill in Badminton, (2) there are significant differences between technique skill of badminton overhead lob forehand on high kinesthetic perception and low kinesthetic perception, and (3) there is no significant interaction between training method (reciprocal and inclusion) and kinesthetic perception on overhead lob forehand technique skill in Badminton.
\end{abstract}

Keyword: reciprocal and inclusion training method, kinesthetic perception, and overhead lob forehand improvement technique in badminton

How to Cite: Tamim, M. (2017). Pengaruh metode latihan (resiprokal dan inklusi) persepsi kinestetik terhadap teknik overhead lob forehand bulu tangkis. Jurnal Keolahragaan, 5(1), 71-80. doi:http://dx.doi.org/10.21831/jk.v5i1.12806

Permalink/DOI: http://dx.doi.org/10.21831/jk.v5i1.12806 


\section{PENDAHULUAN}

Mengajar merupakan bagian dari proses belajar mengajar sehingga didapatkan situasi belajar yang kondusif, efektif, dan efisien. Dalam proses ini terdapat banyak faktor yang memengaruhi, salah satunya adalah pengelolaan kelas. Seorang pelatih harus bisa menguasai keterampilan dasar dan mempunyai kreativitas dalam mengajar agar dapat menciptakan suasana kelas efektif, kondusif, dan efisien pada saat peroses pembelajaran.

Pendidikan pada dasarnya adalah usaha sadar untuk menumbuhkembangkan potensi sumber daya manusia peserta didik dengan cara mendorong dan memfasilitasi kegiatan belajar (Syah, 2003, p. 1). Kegiatan belajar adalah suatu kegiatan tempat seseorang mendapat pengetahuan, peroses belajar mutlak harus dilakukan setiap orang baik secara sadar maupun tidak sadar.

Sebagai salah satu mata pelajaran wajib di sekolah, Lutan (2000, p.1) menjelaskan bahwa pendidikan jasmani merupakan wahana dan alat untuk membina anak agar kelak mampu membuat keputusan terbaik tentang aktivitas jasmani yang dilakukan dan menjalani pola hidup. Di lain pihak, Kurikulum 2013 mengharapkan peserta didik agar mampu mempraktikkan variasi dan kombinasi teknik dasar salah satu permainan dan olahraga dengan tepat dan lancar serta nilai kerja sama, toleransi, percaya diri, keberanian, menghargai lawan, bersedia berbagi tempat dan peralatan. Harapan lainnya adalah siswa diharapkan mampu menentukan variasi dan kombinasi teknik dasar berbagai permainan dalam pendidikan jasmani.

Dilihat dari aspek hasil belajar peserta didik, dalam pendidikan jasmani khususnya pada olahraga bulu tangkis memerlukan suatu metode pembelajaran yang tepat guna, karena hal ini akan berpengaruh signifikan pada tingkat keberhasilan (tercapainya suatu tujuan pembelajaran). Oleh karena itu metode ini harus dirancang dengan sebaik mungkin dan mengacu pada kriteria yang menjadi acuan ranah penilaian proses pembelajaran atlet yaitu kognitif, afektif, dan psikomotor pada olahraga bulu tangkis.

Di Indonesia, permainan bulu tangkis yang merupakan bagian dari mata pelajaran pendidikan jasmani juga merupakan salah satu cabang olahraga permainan yang banyak diminati oleh masyarakat umum mulai kelompok umur anak-anak, pemula, remaja, hingga kelompok umur taruna. Hal ini terbukti dengan banyak berdirinya klub-klub bulu tangkis dan diselenggarakannya berbagai kejuaraan bagi kelompok umur tersebut (rutinitas tahunan) sebagai ajang penyaluran bakat dan pencapaian prestasi.

Menurut Subardjah (2000, p.13) permainan bulu tangkis merupakan permainan yang bersifat individual yang dapat dilakukan dengan cara satu orang melawan satu orang atau dua orang melawan dua orang. Permainan ini menggunakan raket sebagai alat pemukul dan kok (shuttlecock) sebagai objek pukul, lapangan permainan berbentuk segi emapat dan dibatasi oleh net untuk memisahkan antara daerah permainan sendiri dan daerah permainan lawan. Tujuan permainan bulu tangkis adalah berusaha untuk menjatuhkan shuttlecock di daerah permainan lawan dan berusaha agar lawan tidak dapat memukul shuttlecock dan menjatuhkannya di daerah permainan sendiri.

Bulu tangkis merupakan olahraga yang dimainkan dengan melewati net menggunakan raket dan kok pada teknik yang bervariasi dari yang relatif melakukan gerakan lambat sampai gerakan cepat. Permainan bulu tangkis adalah permainan yang bersifat individual yang dapat dilakukan dengan cara satu lawan satu atau dua lawan dua dengan menggunakan raket sebagai alat pemukul dan kok sebagai objek pukul.

Dalam dunia olahraga bulu tangkis, suatu latihan dapat tercapai jika atlet telah menguasai beberapa faktor yang dapat menunjang terhadap pencapaian yang maksimal di antaranya adalah kondisi fisik, teknik, taktik, dan mental. Selain faktor-faktor tersebut, untuk suatu pembelajaran puncak dalam olahraga bulu tangkis, perlu adanya aplikasi pembelajaran atau program latihan yang dirancang dengan baik, dukungan sarana pembelajaran yang memadai, serta terciptanya suasana yang menyenangkan. Permainan bulu tangkis memiliki berbagai macam teknik dasar pukulan. Di dalam permainan bulu tangkis yang harus dikuasai oleh seorang pemain, di antaranya adalah long service, short service, lob, smash, drop shot, drive dan netting (Hidayat, Bumi, \& Alamsyah, 2010, p. 140). Sejalan dengan pemikiran tersebut diambil salah satu saja yang merupakan dari teknik dasar bulutangkis, dalam hal ini dipilih teknik dasar $l o b$ khususnya pada overhead lob forehand.

Pukulan overhead lob forehand merupakan pukulan yang dilakukan dari atas kepala dengan cara menerbangkan kok melambung ke arah belakang (Anonim, 2012). Pukulan overhead clear atau pukulan lob harus benar-benar dikuasai, karena pukulan ini sama dengan bebe- 
rapa pukulan lainnya. Pukulan lob merupakan pukulan jauh dengan hasil pukulan melambung dengan diarahkan sedekat mungkin pada bagian garis belakang lapangan lawan. Dalam melakukan lob forehand ini digunakan pegangan forehand dengan cara seperti berjabat tangan pada ibu jari dan telunjuk berbentuk huruf "V" posisi tangan diletakkan pada bagian gagang raket.

Pada saat dilakukan observasi awal di SMP Negeri 1 Pringgasela dan SMPN 2 Masbagik, atlet rata-rata kurang termotivasi ketika pembelajaran pada materi bulu tangkis. Akibatnya, ketika proses pembelajaran berlangsung siswa cenderung pasif dan sering mengeluh dalam melakukan berbagai kombinasi teknik dasar bulu tangkis tersebut. Permasalahan yang muncul adalah bahwa pelatih kurang memiliki pengetahuan dalam pemilihan metode latihan yang cukup dalam mengajarkan teknik dasar bulu tangkis, terutama tentang pengetahuan dasar yang mendukung dalam menerapkan metode latihan untuk mempermudah atlet melakukan berbagai kombinasi teknik-teknik dasar yang baik. Untuk itu dibutuhkan metode lain (metode berbeda) yang tepat guna sebagai solusi untuk merangsang atlet agar lebih aktif dalam pembelajaran khususnya materi bulu tangkis. Tentunya hal ini menuntun pelatih supaya lebih kreatif dalam hal memilih metode dan tidak terpaku hanya pada satu metode saja. Dalam hal ini dikemukakan suatu metode latihan yang berbeda dengan metode latihan sebelumnya yakni resiprokal dan inklusi yang diasumsikan akan membantu pemecahan permasalahan pembelajaran atlet tersebut.

Kedua metode latihan ini (resiprokal dan inklusi) masing-masing mempunyai perbedaan. Gaya resiprokal adalah pengembangan dari gaya latihan yang ditingkatkan pelaksanaannya untuk memperbesar hubungan sosialisasi dengan teman serta mengambil manfaat dari adanya umpan balik dengan segera (Mosston, Ashworth, \& Block, 2008, p. 62). Gaya mengajar resiprokal yang dijadikan sebagai metode latihan menekankan kepada atlet untuk berperan dalam hal pemberian tanggung jawab yang bergeser dari pelatih ke teman sebaya dalam proses pembelajaran. Dalam peran ini atlet dapat dibagi menjadi dua kelompok, ada atlet yang berperan sebagai pelaku, dan atlet lainnya sebagai observer (pengamat) untuk pelatih berfungsi sebagai fasilitator.

Melalui upaya mengevaluasi aktivitas temannya, diharapkan atlet juga mengetahui konsep pelaksanaan yang benar, karena setiap atlet akan berperan sebagai observer (pengamat), atlet akan berupaya untuk menguasai konsep geraknya yang benar. Untuk pelaksanaan gaya resiprokal, atlet terlebih dahulu harus mempelajari teknik dasar, dan gaya resiprokal ini dilaksanakan pada pembelajaran teknik lanjutan.

Gaya mengajar inklusi merupakan gaya mengajar yang memperkenalkan berbagai tingkat tugas yang berbeda (Suryobroto, 2001, p. 62). Gaya mengajar inklusi yang dijadikan sebagai metode latihan lebih menekankan kepada atlet untuk mencari sendiri tingkat tugas yang berbeda dalam menentukan kegiatan yang sesuai dengan kemampuan atlet sendiri. Dalam metode latihan inklusi atlet diberi kesempatan untuk mengevaluasi kemampuan dirinya, atas dasar lembar kriteria kemampuan yang telah dibuat oleh pelatih dan mengambil keputusan untuk berpindah pada tingkatan yang lebih tinggi. Mostton \& Ashworth (Chatoupis \& Emmanuel, 2003, p. 33) adapun tugas pelatih dalam gaya inklusi adalah untuk mempersiapkan tugas-tugas dan tingkat kesulitan dalam setiap tugas. Atlet bebas memilih aktivitas yang mereka anggap sesuai dengan kemampuannya (atlet) sendiri. Atlet diberi kesempatan untuk mengevaluasi kemampuan dirinya atas dasar lembar kriteria kemampuan yang telah dibuat oleh pelatih dan mengambil keputusan untuk berpindah level yang ada di atasnya (yang lebih tinggi). Untuk pelaksanaan gaya inklusi, atlet terlebih dahulu harus pernah melakukan pembelajaran teknik dasar.

Gaya melatih inklusi ini memiliki pengaruh besar, salah satu keuntungan yang sangat penting dari gaya ini, bisa memperhatikan perbedaan atlet. Mengembangkan konsep sendiri dalam melakukan berbagi kegiatan yang berkaitan dengan penampilan fisik. Dalam hal ini atlet bisa mengevaluasi kekurangan dan kelebihan yang dimiliki berdasarkan tingkat tugas yang akan dilakukan dengan pengetahuan atlet itu sendiri.

Berdasarkan uraian permasalahan, peneliti tertarik untuk memberikan eksperimental berupa treatment dalam bentuk metode latihan yakni resiprokal dan inklusi. Tujuan agar atlet lebih aktif dan kreatif dalam proses pembelajaran terkait materi bulu tangkis khususnya pada teknik dasar pukulan overhead lob forehand.

\section{METODE}

Penelitian ini menggunakan desain penelitian eksperimen faktorial. Pada penelitian 
ini desain eksperimen dengan dua faktor yang masing-masing terdiri atas dua taraf. Data dalam penelitian ini dianalisis dengan desain faktorial $2 \mathrm{X} 2$. Ini berdasarkan jumlah variabel yang ada, yaitu: (a) Variabel independen yaitu: gaya mengajar (resiprokal dan inklusi) dan persepsi kinestetik. (b) Variabel dependen yaitu: keterampilan teknik pukulan overhead lob forehand pada bulu tangkis. Rancangan faktorial $2 \times 2$ dapat digambarkan dalam Tabel 1.

Tabel 1. Rancangan Faktorial 2x2

\begin{tabular}{ccc}
\hline & \multicolumn{2}{c}{ Persepsi kinestetik (B) } \\
\cline { 2 - 3 } Metode & Persepsi & Persepsi \\
Latihan (A) & $\begin{array}{c}\text { Kinestetik Tinggi } \\
\left(\mathbf{B}_{1}\right)\end{array}$ & $\begin{array}{c}\text { Kinestetik Rendah } \\
\left(\mathbf{B}_{2}\right)\end{array}$ \\
\hline $\begin{array}{c}\text { Resiprokal } \\
\left(\mathrm{A}_{1}\right)\end{array}$ & $\mathrm{A}_{1} \mathrm{~B}_{1}$ & $\mathrm{~A}_{1} \mathrm{~B}_{2}$ \\
Inklusi & & \\
$\left(\mathrm{A}_{2}\right)$ & $\mathrm{A}_{2} \mathrm{~B}_{1}$ & $\mathrm{~A}_{2} \mathrm{~B}_{2}$ \\
\hline
\end{tabular}

Keterangan:

$A_{1} B_{1}:$ Metode latihan resiprokal dengan persepsi kinestetik tinggi.

$A_{1} B_{2}$ : Metode latihan resiprokal dengan persepsi kinestetik rendah.

$A_{2} B_{1}$ : Metode latihan inklusi dengan persepsi kinestetik tinggi.

$A_{2} B_{2}$ : Metode latihan inklusi dengan persepsi kinestetik rendah.

Penelitian ini dilaksanakan di SMP Negeri 1 Pringgasela dan SMPN 2 Masbagik. Waktu penelitian dilaksanakan mulai dari bulan Februari sampai dengan April 2014.

Populasi dalam penelitian ini berjumlah 66 siswa di kelas IX SMPN 1 Pringgasela dan SMPN 2 Masbagik Kabupaten Lombok Timur Nusa Tenggara Barat. Teknik pengabilan sampel dalam penelitian ini menggunakan purposive random sampling yaitu suatu teknik pengambilan sampel berdasarkan ciri-ciri tertentu atau sesuai kebutuhan yang diperlukan dalam penelitian ini. Dari tiap-tiap sekolah diambil satu kelas sebagai kelas eksperimen dengan masingmasing kelas terdiri atas 33 orang untuk kelas IX5 di SMPN 1 Pringgasela diberi perlakuan gaya mengajar, sedangkan untuk kelas IX 3 di SMPN 2 Masbagik diberi perlakuan gaya mengajar resiprokal. Langkah untuk menganalisis adalah sebagai berikut: (a) mengatur tes dalam rangka menentukan skor tinggi dan skor rendah, (b) menentukan $27 \%$ skor tinggi dan $27 \%$ skor rendah dengan menempatkan dalam satu kelompok yang sama (Baumgartner, Jackson, Mahar, \& Rowe, 2007, p. 463).
Teknik penentuan sampel diawali dengan tes persepsi kinestetik dengan populasi yang berjumlah 66 orang, siswa SMPN 1 Pringgasela berjumlah 33 orang dan siswa SMPN 2 Masbagik berjumlah 33 orang. Kemudian diujikan kemampuan persepsi kinestetik dari siswa yang berjumlah 66 orang yang berasal dari dua sekolah, yaitu dengan menggunakan tes perception distance jump. Dari hasil tes kemudian diranking dan diambil $27 \%$ subjek yang memiliki kemampuan persepsi kinestetik tinggi dan kinestetik rendah dari 33 orang siswa selanjutnya 27 $\%$ subjek yang memiliki kemampuan persepsi kinestetik tinggi dan kinestetik rendah dari 33 siswa diambil sebagai sampel. Setelah dilakukan tes, didapatlah sebanyak 9 orang yang memiliki kemampuan kinestetik tertinggi dan 9 orang yang memiliki kemampuan kinestetik terendah. Pada ranking tengah tidak digunakan sebagai sampel, yaitu sebanyak 15 orang. Jadi, jumlah sampel yang telah diambil terdiri atas 9 sampel yang memiliki kemampuan kinestetik tinggi dan 9 sampel yang memiliki kemampuan kinestetik rendah, dan keseluruhannya yaitu berjumlah 18 siswa di SMPN 1 Pringgasela dan 18 siswa di SMPN 2 Masbagik.

Variabel penelitian ini terdiri atas variabel independen, variabel dependen, dan variabel moderator. Sugiyono (2010, p. 39) menjelaskan variabel independen merupakan variabel yang memengaruhi (memperkuat dan memperlemah) variabel lain, variabel dependen merupakan variabel yang dipengaruhi oleh variabel lain, sedangkan variabel moderator merupakan variabel yang memengaruhi hubungan antara variabel independen dan dependen. Variabel independen pada penelitian ini, yaitu metode latihan (resiprokal dan inklusi). Variabel dependen pada penelitian ini, yaitu overhead lob forehand bulu tangkis. Variabel atributif pada penelitian ini, yaitu (a) persepsi kinestetik tinggi, (b) persepsi kinestetik rendah.

Data yang diperoleh dalam penelitian ini adalah data kuantitatif. Pengumpulan data diperoleh dengan menggunakan teknik tes dan pengukuran. Instrumen yang digunakan dalam pengumpulan data penelitian ini adalah: (1) tes persepsi kinestetik yang digunakan untuk mengukur persepsi kinestetik adalah untuk menentukan tingkat persepsi kinestetik siswa kelas IX SMPN 1 Pringgasela dan SMPN 2 Masbagik dalam kategori persepsi kinestetik tinggi dan persepsi rendah dengan melakukan tes perception distance jump (Johnson \& Nelson, 1986, p. 441), (2) tes forehand clear (lob) bulu tangkis, 
Jurnal Keolahragaan 5 (1), April 2017 - 75

Muhammad Husni Tamim

dalam penelitian ini keterampilan teknik dasar bulu tangkis yang diambil adalah overhead lob forehand. Kegunaan utama tes ini adalah untuk mengukur kekuatan memukul shuttle cock (Nurhasan, 2000, p. 182).

Validitas adalah seberapa jauh ketepatan dan kecermatan suatu alat ukur dalam melakukan fungsi ukurannya atau memberikan hasil ukur yang sesuai dengan maksud dilakukannya pengukuran tersebut keandalan akan bergantung pada seberapa ketat tes yang dilakukan individu dan tingkat motivasi untuk melakukan tes. Sulistyo (2010, p. 40) menyatakan "ketepatan atau kecermatan suatu instrumen dalam pengukuran. Dalam pengujian instrumen pengumpulan data, validitas dibedakan menjadi validitas faktor dan validitas item."

Tes persepsi kinestetik yang diukur dengan tes perception distance jump dengan mempunyai validitas dan reliabilitas sebesar 0,98 yang digunakan untuk mencari dan menentukan sampel yang masuk kategori persepsi kinestetik tinggi dan rendah. Tes pukulan overhead lob forehand yang digunakan Clear tes menurut French (Nurhasan, 2000, p. 184) tes ini dengan kriteria ranking tournament setengah kompetisi mempunyai validitas 0,60 sedangkan reliabilitas 0,96 dengan ood-oven method.

Teknik analisis data yang digunakan dalam penelitian ini: (1) uji normalitas sampel adalah pengujian terhadap normal tidaknya data yang dianalisis. Uji yang digunakan adalah uji kolmogorov smirnov, (2) uji homogenitas dimaksudkan untuk meyakinkan agar kelompok yang membentuk sampel berasal dari populasi yang sama. Uji homogenitas menggunakan uji Levene's Test dengan uji F, (3) pengujian hipotesis penelitian dilakukan dengan menggunakan analisis variansi (Anava) yaitu dengan menggunakan program software SPSS version 20.0 for windows dengan taraf signifikansi $5 \%$ atau 0,05 . Uji ini dilakukan untuk mengetahui perbedaan rerata nilai dari variabel antara pretest dan posttest pada kelompok eksperimen dan mengetahui perbedaan pengaruh antar variabel.

\section{HASIL DAN PEMBAHASAN}

Deskripsi hasil analisis data tes hasil pretest dan posttest pada pukulan overhead lob forehand bulu tangkis yang dilakukan di SMPN 1 Pringgasela dan SMPN 2 Masbagik diterapkan metode latihan resiprokal dan inklusi berdasarkan persepsi kinestetik.
Tabel 2. Metode Latihan Resiprokal

\begin{tabular}{cccc}
\hline No. & Pretest & Posttest & Persepsi Kinestetik \\
\hline 1. & 75 & 82 & Tinggi \\
2. & 69 & 78 & Tinggi \\
3. & 70 & 80 & Tinggi \\
4. & 76 & 82 & Tinggi \\
5. & 68 & 74 & Tinggi \\
6. & 74 & 86 & Tinggi \\
$7 .$. & 70 & 82 & Tinggi \\
8. & 65 & 78 & Tinggi \\
9. & 70 & 84 & Tinggi \\
10. & 72 & 80 & Rendah \\
11. & 60 & 68 & Rendah \\
12. & 65 & 76 & Rendah \\
13. & 68 & 80 & Rendah \\
14. & 60 & 77 & Rendah \\
15. & 66 & 76 & Rendah \\
$16 .$. & 70 & 82 & Rendah \\
17. & 65 & 78 & Rendah \\
18. & 60 & 74 & Rendah \\
\hline
\end{tabular}

Tabel 3. Metode Latihan Inklusi

\begin{tabular}{cccc}
\hline No. & Pretest & Posttest & Persepsi Kinestetik \\
\hline 1. & 70 & 83 & Tinggi \\
2. & 73 & 88 & Tinggi \\
3. & 75 & 78 & Tinggi \\
4. & 65 & 83 & Tinggi \\
5. & 76 & 92 & Tinggi \\
6. & 78 & 91 & Tinggi \\
7. & 64 & 79 & Tinggi \\
8. & 70 & 83 & Tinggi \\
$9 .$. & 75 & 89 & Tinggi \\
10. & 72 & 77 & Rendah \\
11. & 76 & 80 & Rendah \\
12. & 70 & 80 & Rendah \\
13. & 67 & 79 & Rendah \\
14. & 66 & 78 & Rendah \\
15. & 62 & 80 & Rendah \\
16. & 66 & 81 & Rendah \\
17. & 60 & 78 & Rendah \\
18. & 60 & 80 & Rendah \\
\hline
\end{tabular}

Uji normalitas data dalam penelitian ini digunakan metode kolmogorov smirnov. Hasil uji normalitas data yang dilakukan pada seluruh kelompok perlakuan, analisis dilakukan dengan program software SPSS version 20.0 for windows dengan taraf signifikansi 5\% atau 0,05.

Tabel 3. Rangkuman Hasil Uji Normalitas

\begin{tabular}{ccc}
\hline Kelompok Perlakuan & Sig. & Kesimpulan \\
\hline $\mathrm{A}_{1} \mathrm{~B}_{1}(\mathrm{KP} 1)$ & & \\
$\mathrm{A}_{1} \mathrm{~B}_{2}(\mathrm{KP} 2)$ & 0.890 & Normal \\
$\mathrm{A}_{2} \mathrm{~B}_{1}(\mathrm{KP} 3)$ & & \\
$\mathrm{A}_{2} \mathrm{~B}_{2}(\mathrm{KP} 4)$ & & \\
\hline
\end{tabular}

Keterangan:

$A_{1} B_{1}$ : Kelompok yang mengikuti metode latihan resiprokal dengan kategori persepsi kinestetik tinggi. 
$A_{1} B_{2}$ : Kelompok yang mengikuti metode latihan resiprokal dengan kategori persepsi kinestetik rendah.

$A_{2} B_{1}$ : Kelompok yang mengikuti metode latihan inklusi dengan persepsi kinestetik tinggi.

$\mathrm{A}_{2} \mathrm{~B}_{2}$ : Kelompok yang mengikuti metode latihan inklusi dengan kategori persepsi kinestetik rendah.

Uji normalitas data dilakukan untuk mengetahui data penelitian berdistribusi normal atau tidak. Kriteria pengambilan keputusan adalah apabila $\mathrm{p}>0,05, \mathrm{H}_{0}$ diterima dan $\mathrm{H}_{1}$ ditolak, berarti dapat disimpulkan bahwa data sampel tersebut berdistribusi normal. Demikian pula sebaliknya apabila $\mathrm{p}<0,05, \mathrm{H}_{0}$ ditolak dan $\mathrm{H}_{1}$ diterima, berarti dapat disimpulkan bahwa data sampel tersebut berdistribusi tidak normal.

Berdasarkan analisis statistik uji normalitas yang telah dilakukan dengan menggunakan uji kolmogorov smirnov, didapatkan dari hasil uji normalitas data yang dilakukan pada keseluruhan kelompok perlakuan diperoleh nilai sebesar 0,89, nilai tersebut lebih besar dari angka 0,005, dengan demikian dapat disimpulkan data yang diperoleh berdistribusi normal. Artinya, data pada tes akhir seluruh kelompok perlakuan terbukti berdistribusi normal dan telah memenuhi uji prasyarat sehingga persyaratan untuk penggunaan statistik parametrik dalam analisis data sudah dipenuhi.

Uji homogenitas dimaksudkan untuk menguji kesamaan varians antara kelompok 1 dengan kelompok 2. Uji homogenitas pada penelitian ini dilakukan dengan uji levene test. Hasil uji homogenitas data antara kelompok 1 dan kelompok 2 adalah sebagai berikut: (1) uji homogenitas pada kelompok yang dimaksud kelompok perlakuan adalah uji homogenitas data skor kelompok keterampilan pukulan overhead lob forehand yang diajarkan dengan gaya mengajar resiprokal dan gaya mengajar inklusi. Uji homogenitas pada kelompok perlakuan ini menggunakan uji levene test.

Tabel 4. Hasil Uji Homogenitas Varians pada Metode Latihan

\begin{tabular}{ccccc}
\hline \multicolumn{2}{c}{ Kelompok } & $\begin{array}{c}\text { Lavene } \\
\text { Statistic }\end{array}$ & Sig. & Ket. \\
\cline { 1 - 2 } $\begin{array}{c}\text { Kelompok } \\
\mathrm{A}_{1} \mathrm{~A}_{2}\end{array}$ & $\begin{array}{c}\text { resiprokal } \\
\text { Inklusi }\end{array}$ & 2.607 & 0.116 & Homogen \\
\hline
\end{tabular}

Berdasarkan analisis statistik uji homogenitas yang telah dilakukan dengan menggunakan uji Levene Test, diperoleh nilai signifikansi sebesar 0,116>0,05. Hal ini berarti dalam kelompok data memiliki varians yang homogen.
Artinya, data tes akhir pada kelompok metode latihan yakni resiprokal dan inklusi bertaraf homogen. Hal ini berarti data setiap metode latihan merupakan statistik parametrik, (2) uji homogenitas antar kelompok perlakuan ini menggunakan uji levene test. Rangkuman hasil uji homogenitas varians antar kelompok perlakuan dapat dilihat Tabel 5.

Tabel 5. Hasil Uji Homogenitas Varians Antara Kelompok Latihan

\begin{tabular}{cccc}
\hline Kelompok & Lavene Statistic & Sig. & Keterangan \\
\hline $\mathrm{A}_{1} \mathrm{~B}_{1}$ & & & \\
$\mathrm{~A}_{1} \mathrm{~B}_{2}$ & 3.891 & 0.18 & Homogen \\
$\mathrm{A}_{2} \mathrm{~B}_{1}$ & & & \\
$\mathrm{~A}_{2} \mathrm{~B}_{2}$ & & & \\
\hline
\end{tabular}

Keterangan:

$\mathrm{A}_{1} \mathrm{~B}_{1}$ : Kelompok yang mengikuti metode latihan resiprokal dengan kategori persepsi kinestetik tinggi.

$\mathrm{A}_{1} \mathrm{~B}_{2}$ : Kelompok yang mengikuti metode latihan resiprokal dengan kategori persepsi kinestetik rendah.

$\mathrm{A}_{2} \mathrm{~B}_{1}$ : Kelompok yang mengikuti metode latihan inklusi dengan persepsi kinestetik tinggi.

$\mathrm{A}_{2} \mathrm{~B}_{2}$ : Kelompok yang mengikuti metode latihan inklusi dengan kategori persepsi kinestetik rendah.

Berdasarkan analisis statistik uji homogenitas yang telah dilakukan dengan menggunakan uji levene test, diperoleh nilai signifikansi sebesar 0,18>0,05. Hal ini berarti dalam penelitian ini keempat kelompok data memiliki varians yang homogen. Artinya data pada tes akhir seluruh kelompok perlakuan terbukti bertaraf homogen dan telah memenuhi uji prasyarat sehingga persyaratan untuk penggunaan statistik parametrik dalam analisis data sudah dipenuhi.

Pengujian hipotesis dalam penelitian ini menggunakan analisis varians (Anava) dua jalur. Pengujian hipotesis penelitian dilakukan berdasarkan hasil analisis data dan analisis varian. Analisis varians dua jalur digunakan untuk menguji pengaruh utama (main effect) antara variabel bebas gaya mengajar dan persepsi kinestetik (simple effect) terhadap variabel terikat teknik overhead lob forehand. Hasil analisis data yang diperlukan untuk pengujian hipotesis adalah sebagai berikut: (1) uji hipotesis yang berbunyi Ha: terdapat perbedaan pengaruh metode latihan terhadap peningkatan teknik overhead lob forehand pada bulu tangkis, dan Ho: tidak terdapat perbedaan pengaruh metode latihan terhadap peningkatan teknik overhead lob forehand pada bulu tangkis. 
Jurnal Keolahragaan 5 (1), April 2017 - 77

Muhammad Husni Tamim

Tabel 6. Hasil Perhitungan Metode Latihan terhadap Peningkatan Pukulan Overhead Lob Forehan Bulu Tangkis

\begin{tabular}{cccccc}
\hline Source & $\begin{array}{c}\text { Sum of } \\
\text { squares }\end{array}$ & df & $\begin{array}{c}\text { Mean } \\
\text { Square }\end{array}$ & F & Sig. \\
\hline Metode & 106,778 & 1 & 106,778 & 7,248 & 0,010 \\
\hline
\end{tabular}

Hasil penelitian menunjukkan bahwa ada perbedaan pengaruh metode latihan resiprokal dan inklusi terhadap peningkatan teknik overhead lob forhean pada bulu tangkis. Hal ini dibuktikan dengan nilai sig sebesar 0,010 $<0,05$ artinya Ho ditolak, Ha diterima. Artinya terdapat perbedaan pengaruh metode latihan yakni resiprokal dan inklusi terhadap peningkatan teknik overhead lob forehand pada bulu tangkis, (2) uji hipotesis yang berbunyi Ha: terdapat pengaruh persepsi kinestetik terhadap peningkatan teknik overhead lob forehand pada bulu tangkis, dan Ho: tidak terdapat pengaruh persepsi kinestetik terhadap peningkatan teknik overhead lob forehand pada bulu tangkis. Berikut ini adalah rangkuman hasil analisis penghitungan persepsi kinestetik tinggi dan persepsi kinestetik rendah terhadap peningkatan teknik overhead lob forehand pada bulu tangkis.

Tabel 7. Data Hasil Analisis

\begin{tabular}{cccccc}
\hline Source & $\begin{array}{c}\text { Sum of } \\
\text { squares }\end{array}$ & df & $\begin{array}{c}\text { Mean } \\
\text { Square }\end{array}$ & F & Sig. \\
\hline $\begin{array}{c}\text { Persepsi } \\
\text { kienestetik }\end{array}$ & 215,111 & 1 & 215,111 & 14,964 & 0,001 \\
\hline
\end{tabular}

Hasil penelitian menunjukkan bahwa ada perbedaan antara persepsi kinestetik tinggi dan persepsi kinestetik rendah terhadap peningkatan teknik overhead lob forehand pada bulu tangkis. Hal ini dibuktikan dengan nilai sig sebesar 0,001 $<$ 0,05, artinya, Ho ditolak, Ha diterima. Artinya, terdapat perbedaan yang signifikan antara persepsi kinestetik tinggi dan persepsi kinestetik rendah terhadap peningkatan teknik overhead lob forehand pada bulu tangkis, (3) uji hipotesis yang berbunyi Ha: terdapat interaksi antara metode latihan (resiprokal dan inklusi) dan persepsi kinestetik terhadap keterampilan teknik overhead lob forehand pada bulu tangkis, dan Ho: tidak terdapat interaksi antara metode latihan (resiprokal dan inklusi) dan persepsi kinestetik terhadap keterampilan teknik overhead lob forehand pada bulu tangkis. Berikut ini adalah rangkuman hasil analisis penghitungan interaksi antara metode latihan (resiprokal dan inklusi) dan persepsi kinestetik terhadap keterampilan teknik overhead lob forehand pada bulu tangkis.
Tabel 8. Data Hasil Analisis

\begin{tabular}{cccccc}
\hline \multicolumn{1}{c}{ Source } & $\begin{array}{c}\text { Sum of } \\
\text { squares }\end{array}$ & $\begin{array}{c}\text { Mean } \\
\text { Square }\end{array}$ & F & Sig. \\
\hline $\begin{array}{l}\text { Interaksi metode } \\
\text { dengan persepsi } \\
\text { kinestetik }\end{array}$ & 9,000 & 1 & 9,000 & 0,626 & 0,435 \\
\hline
\end{tabular}

Penghitungan interaksi antara metode latihan (resiprokal dan inklusi) dan persepsi kinestetik terhadap keterampilan teknik overhead lob forehand pada bulu tangkis sebesar 9,000 . Nilai signifikansi interaksi antara gaya mengajar (resiprokal dan inklusi) dan persepsi kinestetik terhadap keterampilan teknik overhead lob forehand pada bulu tangkis sebesar $0,435>0,05$, maka Ho yang menyatakan tidak ada interaksi, diterima. Artinya, tidak terdapat interaksi antara metode latihan (resiprokal dan inklusi) dan persepsi kinestetik terhadap keterampilan teknik overhead lob forehand pada bulu tangkis.

Pembahasan hasil penelitian ini memberikan penafsiran yang lebih lanjut mengenai hasilhasil analisis data yang telah dikemukakan, berdasarkan pengujian hipotesis yang telah dilakukan. Kesimpulan analisis tersebut dapat dipaparkan lebih lanjut sebagai berikut: (1) dalam rangka mengetahui metode mana yang lebih baik untuk digunakan sebagai metode pembelajaran pukulan overhead lob forehand dalam cabang olahraga bulu tangkis, diperlukan suatu indikator yang digunakan sebagai pemisah antara tingkat keterampilan dasar yang dimiliki oleh atlet sebelum diberi pembelajaran. Persepsi kinestetik merupakan salah satu bentuk indikator yang dapat memisahkan tingkat keterampilan dasar atlet yang akan diberi pembelajaran, tepatnya adalah keterampilan gerak motorik yang berhubungan dengan pancaindra. Pembahasan hasil penelitian ini memberikan penafsiran yang lebih lanjut mengenai hasil-hasil analisis data yang telah dipaparkan.

Berdasarkan pengujian hipotesis pertama ternyata ada perbedaan pengaruh yang nyata antara kelompok atlet yang mendapatkan metode latihan resiprokal dan kelompok atlet yang mendapatkan metode latihan inklusi terhadap peningkatan hasil belajar pukulan overhead lob forehand pada bulu tangkis. Kelompok atlet yang mendapat metode latihan resiprokal mempunyai peningkatan hasil belajar pukulan overhead lob forehand bulu tangkis yang lebih rendah dibandingkan dengan kelompok atlet yang mendapat metode latihan inklusi.

Diterimannya hipotesis yang menyatakan bahwa ada perbedaan pengaruh yang nyata 
antara kelompok atlet yang mendapatkan gaya mengajar resiprokal dan kelompok atlet yang mendapatkan gaya mengajar inklusi terhadap peningkatan hasil belajar pukulan overhead lob forehand bulu tangkis dapat dijelaskan dari berbagai teori yang ada dan pengamatan langsung yang dilakukan oleh peneliti. Gaya resiprokal adalah pengembangan dari gaya latihan yang ditingkatkan pelaksanaannya untuk memperbesar hubungan sosialisasi dengan teman serta mengambil manfaat dari adanya umpan balik dengan segera (Mosston et al., 2008, p. 62). Berdasarkan hasil pengamatan selama berlangsungnya penelitian bahwa pada pembelajaran pukulan overhead lob forehand bulu tangkis yang diajarkan dengan gaya resiprokal terlihat bahwa atlet mudah memahami materi yang disampaikan, karena dalam metode ini atlet saling berpasangan, satu atlet menjadi pengamat (observer) dan satu atlet menjadi pelaku. Hal tersebut menyebabkan setiap gerakan yang salah akan lebih mudah terkoreksi, sehingga pembelajaran materi pukulan overhead lob forehand bulu tangkis dengan menggunakan metode resiprokal cukup baik dalam meningkatkan ketermpilam siswa.

Hipotesis yang menyatakan bahwa ada pengaruh gaya mengajar inklusi terhadap keterampilan teknik dasar bulu tangkis diterima, disebabkan oleh beberapa hal dan juga dapat dijelaskan dari berbagai teori yang ada dan pengamatan langsung yang dilakukan oleh peneliti. Inklusi merupakan metode pembelajaran yang memperkenalkan berbagai tingkat tugas kepada atlet (Suryobroto, 2001, p. 62). Gaya mengajar inklusi yang dijadikan sebagai metode latihan, atlet dapat diberi kemudahan dan cepat bisa memahami sekaligus bisa mengoreksi sendiri tingkat kemampuan yang dimilikinya. Dalam gaya mengajar inklusi lebih menekankan kepada peserta didik untuk mencari sendiri tingkat tugas yang berbeda dalam menentukan tingkat kegiatan yang sesuai dengan kemampuan atlet itu sendiri. (2) Alasan diterimanya hipotesis yang menyatakan bahwa ada perbedaan yang signifikan antara keterampilan teknik dasar bulu tangkis pada persepsi kinestetik tinggi dan persepsi kinestetik rendah adalah atletdengan persepsi kinestetik tinggi mempunyai peningkatan hasil belajar teknik pukulan overhead lob forehand pada bulu tangkis lebih baik dibanding kelompok atlet dengan persepsi kinestetik rendah. Atlet yang memiliki persepsi kinestetik tinggi mempunyai potensi yang lebih besar untuk menguasai keterampilan gerak yang baru dipelajari daripada atlet yang memiliki persepsi kinestetik rendah. Menurut Djamarah (2000, p. 12). kinestetik adalah kemampuan seseorang untuk menggerakkan suatu objek dan keterampilan-keterampilan fisik yang halus. Persepsi kinestetik adalah kemampuan seluruh tubuh selama otot bereaksi dan berhubungan dengan indra (Johnson \& Nelson, 1986, p. 440). Kinestetik dapat memberikan kesadaran akan posisi tubuh atau bagian-bagian tubuh yang bergerak, juga mengenal kontraksi otot dan keseimbangan tubuh. Hal tersebut akan mengontrol gerakangerakan yang dilakukan lebih akurat. Dengan kemampuan mengontrol yang lebih akurat berarti kondisi gerakan menjadi semakin baik dan gerakan yang dihasilkan akan lebih efektif. Individu dengan tingkat kinestetik yang tinggi akan lebih mudah untuk melakukan gerakan teknik dasar bulu tangkis. Pemain akan mampu menuju gerakan yang lebih konsisten. Persepsi kinestetik melaksanakan fungsinya melalui suatu mekanisme perseptual. Persepsi kinestetik merupakan unsur yang sangat penting bagi siswa, sebab persepsi kinestetik merupakan dasar dalam pembentukan keterampilan jadi persepsi kinestetik yang baik dapat menunjang kesiapan atlet untuk melakukan pembelajaran keterampilan. Atlet yang memiliki persepsi kinestetik tinggi memiliki kemampuan untuk beradaptasi terhadap keterampilan gerak pada pukulan overhead lob forehand bulu tangkis yang lebih baik, dari pada yang memiliki persepsi kinestetik rendah. (3) Hasil yang telah dikemukankan pada hasil penelitian tersebut bahwa tidak terdapat interaksi yang signifikan antara metode latihan (resiprokal dan inklusi) dan persepsi kinestetik terhadap peningkatan pukulan overhead lob forehand bulu tangkis.

Berdasarkan hasil dari profil plots, atlet yang memiliki persepsi kinestetik tinggi yang diajarkan dengan kedua metode latihan yaitu resiprokal dan inklusi tidak menunjukkan perbedaan pengaruh yang mencolok (tidak signifikan), begitu juga dengan atlet yang memiliki persepsi kinestetik rendah yang diajarkan dengan kedua metode latihan yaitu resiprokal dan inklusi tidak menunjukkan perbedaan hasil belajar yang signifikan.

Jadi dapat disimpulkan bahwa kelompok atlet yang memiliki persepsi kinestetik tinggi diberikan gaya mengajar resiprokal dan inklusi sama-sama mengalami peningkatan pukulan overhead lob forehand pada bulu tangkis. Sebaliknya, kelompok yang memiliki persepsi kinestetik rendah peningkatannya akan lebih rendah 
dengan peningkatan yang terjadi pada kelompok atlet yang memiliki persepsi kinestetik tinggi.

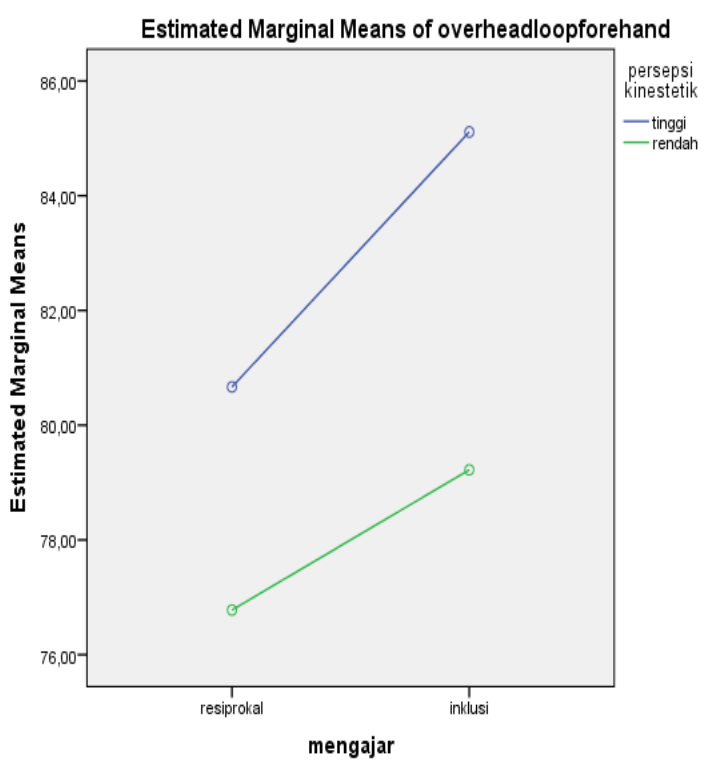

Gambar 1

\section{SIMPULAN DAN SARAN}

\section{Simpulan}

Berdasarkan hasil penelitian yang telah diperoleh dengan analisis data dan pengujian hipotesis, dapat ditarik kesimpulan sebagai berikut: (1) ada perbedaan pengaruh yang signifikan antara metode latihan resiprokal dan inklusi terhadap peningkatan pukulan overhead lob forehand pada bulu tangkis. Pengaruh metode latihan inklusi lebih baik dari pada resiprokal, (2) ada perbedaan terhadap peningkatan pukulan overhead lob forehand pada bulu tangkis yang signifikan antara atlet yang memiliki persepsi kinestetik tinggi dan persepsi kinestetik rendah. Atlet yang memiliki persepsi kinestetik tinggi lebih baik daripada yang memiliki persepsi kinestetik rendah pada pukulan overhead lob forehand bulu tangkis, (3) tidak terdapat interaksi yang signifikan antara metode latihan resiprokal dan inklusi tingkat persepsi kinestetik terhadap peningkatan pukulan overhead lob forehand pada bulu tangkis.

\section{Saran}

Dengan mengacu pada hasil penelitian dan keterbatasan-keterbatasan dalam penelitian, peniliti menyarankan: (1) bagi pelaku bulutangkis (guru dan pelatih), bahwa dalam mengajarkan teknik dasar bulu tangkis khususnya pada pukulan overhead lob forehand bulu tangkis diperlukan metode latihan yang tepat sehingga mendapatkan hasil yang baik dalam proses pem- belajaran, (2) bagi peneliti selanjutnya, agar hasil penelitian ini dapat dijadikan dasar penelitian lanjutan dengan menghubungkan variabel penelitian dengan variabel lain, dan memperdalam kajian tentang metode latihan untuk meningkatkan keterampilan, baik dari segi fisik maupun teknik.

\section{DAFTAR PUSTAKA}

Anonim. (2012). Panduan dan teknik bermain badminton yang benar. Retrieved April 26, 2017, from http://www.cometaarena.com/forum/viewtopic.php? $\mathrm{f}=7 \& \mathrm{t}=3$

Baumgartner, T. A., Jackson, A. (Tony), Mahar, M., \& Rowe, D. (2007). Measurement for evaluation in physical education and exercise science. New York: McGraw-Hill.

Chatoupis, C., \& Emmanuel, C. (2003). Teaching physical education with the inclusion style: The case of a greek elementary school. Journal of Physical Education, Recreation \& Dance, 74(8), 33-38.

http://doi.org/10.1080/07303084.2003.106 08500

Djamarah, S. B. (2000). Guru dan anak didik dalam interaksi edukatif. Jakarta: Rineka Cipta.

Hidayat, Y., Bumi, S. C., \& Alamsyah, R. (2010). Pendidikan jasmani, olahraga, dan kesehatan. Jakarta: Pusat Perbukuan, Kementerian Pendidikan Nasional.

Johnson, B. L., \& Nelson, J. K. (1986). Practical measurements for evaluation in physical education. Minnesota: Burgess Pub.

Lutan, R. (2000). Mengajar pendidikan jasmani. Jakarta: Depdiknas.

Mosston, M., Ashworth, S., \& Block, B. A. (2008). Teaching Physical Education. A Bell \& Howell Company.

Nurhasan. (2000). Tes dan pengukuran pendidikan olahraga. Jakarta: Kurunika.

Subardjah, H. (2000). Bulutangkis. Jakarta: Dedikbud Direktorat Jendral Pendidikan Dasar Kebudayaan dan Menengah.

Sugiyono. (2010). Metode penelitian kuantitatif kualitatif dan $R \& D$. Bandung: Alfabeta.

Sulistyo, J. (2010). 6 hari jago SPSS 17. Yogyakarta: Cakrawala.

Suryobroto, A. S. (2001). Teknologi pembelajaran pendidikan jasmani. 
Jurnal Keolahragaan 5 (1), April 2017 - 80

Muhammad Husni Tamim

Yogyakarta: Fakultas Ilmu Keolahragaan Universitas Negeri Yogyakarta. Retrieved from

http://damaryusti.blogs.uny.ac.id/2016/09/ 30/teknologi-pembelajaran-pendidikanjasmani/

Syah, M. (2003). Psikologi belajar. Jakarta: Pt RajaGrafindo Persada. 